\title{
Measuring socio-economic position in dietary research: is choice of socio-economic indicator important?
}

\author{
Gavin Turrell*, Belinda Hewitt, Carla Patterson and Brian Oldenburg \\ Queensland University of Technology, School of Public Health, Victoria Park Road, Kelvin Grove, Brisbane, \\ Queensland 4059, Australia
}

Submitted 30 April 2002: Accepted 5 September 2002

\begin{abstract}
Objectives: To examine the association between socio-economic position (SEP) and diet, by assessing the unadjusted and simultaneously adjusted (independent) contributions of education, occupation and household income to food purchasing behaviour.

Design: The sample was randomly selected using a stratified two-stage cluster design, and the response rate was $66.4 \%$. Data were collected by face-to-face interview. Food purchasing was examined on the basis of three composite indices that reflected a household's choice of grocery items (including meat and chicken), fruit and vegetables.

Setting: Brisbane City, Australia, 2000.

Participants: Non-institutionalised residents of private dwellings ( $n=1003)$, located in 50 small areas (Census Collectors Districts).

Results: When shopping, respondents in lower socio-economic groups were less likely to purchase grocery foods that were high in fibre and low in fat, salt and sugar. Disadvantaged groups purchased fewer types of fresh fruits and vegetables, and less often, than their counterparts from more advantaged backgrounds. When the relationship between SEP and food purchasing was examined using each indicator separately, education and household income made an unadjusted contribution to purchasing behaviour for all three food indices; however, occupation was significantly related only with the purchase of grocery foods. When education and occupation were simultaneously adjusted for each other, the socio-economic patterning with food purchase remained largely unchanged, although the strength of the associations was attenuated. When household income was introduced into the analysis, the association between education, occupation and food purchasing behaviour was diminished or became non-significant; income, however, showed a strong, graded association with food choice.

Conclusions: The food purchasing behaviours of socio-economically disadvantaged groups were least in accord with dietary guideline recommendations, and hence are more consistent with greater risk for the development of diet-related disease. The use of separate indicators for education, occupation and household income each adds something unique to our understanding of how socio-economic position is related to diet: each indicator reflects a different underlying social process and hence they are not interchangeable, and do not serve as adequate proxies for one another.
\end{abstract}

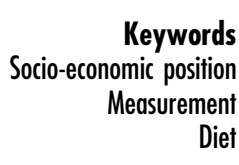

Socio-economic position (SEP) is a widely used concept in dietary research, and is typically operationalised as education, occupation or income ${ }^{1-3}$. Using these types of measures, researchers have investigated the associations between SEP and food and nutrient intakes, and dietary behaviours such as food purchasing. To date, results from food and nutrient intake studies are mixed and sometimes contradictory, and often the socioeconomic differences observed are small ${ }^{4}$. When differences are found, however, it is usually the case that socio-economically disadvantaged groups have an intake profile that parallels their higher levels of mortality and morbidity for chronic disease $\mathrm{s}^{5-8}$. By contrast, socioeconomic differences in dietary behaviour often show a stronger and more consistent pattern of association, with disadvantaged groups being less likely to engage in behaviours that accord with healthy eating messages ${ }^{9,10}$.

The conceptualisation and measurement of SEP in health research more broadly have been extensively discussed and critically examined in a number of 
papers $^{1-3,11,12}$. There is general agreement among these researchers that education, occupation and income are conceptually distinct, that their influence is transmitted by different social processes and, therefore, that they are likely to make separate and unique contributions to the health-related outcome being investigated. In relation to diet, education, for example, might influence food choice by facilitating or constraining one's ability to understand the information communicated in nutrition education messages or on food labels ${ }^{13,14}$. Occupation may affect diet through work-based cultures and social networks ${ }^{4}$. Income reflects the availability of economic and material resources, and directly determines dietary quality by making healthy and nutritious food more affordable and readily accessible ${ }^{15-17}$. The different pathways and processes linking education, occupation and income with diet also have policy and intervention implications. Income-related dietary differences suggest ameliorative responses through the redistributive potential of the taxation and welfare system, whereas differences based on education point to initiatives such as nutrition education programmes ${ }^{11,18}$.

Despite their importance, the use of socio-economic indicators by dietary researchers is characterised by a number of conceptual and analytical problems that ultimately hinder advances in knowledge about how and why SEP is related to diet. Firstly, few dietary researchers provide an explicit rationale or justification for their choice of indicator(s). Whilst it is acknowledged that indicator choice is sometimes constrained by data availability, when more than one indicator is at the researcher's disposal, rarely is the final choice based on conceptual or theoretical considerations. The implicit assumption that appears to be made is that different measures of SEP are interchangeable, and serve as proxies for the one phenomenon. However, this notion is challenged by the results of studies that examine correlations between different socio-economic indicators. Typically, correlations among education, occupation and income are weak to moderate in magnitude ${ }^{11,19,20}$. This suggests some shared association, but, more importantly, highlights the unique contribution of each indicator.

Secondly, while the majority of investigators use two or more indicators of SEP, most do not simultaneously adjust for the unmeasured effects of each indicator on the other ${ }^{21-24}$. Two types of bias may result from this practice. First, if we examine the relationship between SEP and diet using a single indicator such as education, the point estimate (e.g. mean intake) may be biased because the education variable is allowed to account for some of the variation that is actually the product of unmeasured socioeconomic influences. As a result, our claims about the influence of education on diet might be overestimated. Second and relatedly, the use of a single socio-economic indicator may result in the overall or total socio-economic effect being underestimated. For example, some studies examining the relationship between SEP and food and nutrient intakes use a single socio-economic indicator and find only small intake differences between groups ${ }^{7,25}$. If, however, multiple indicators were used and modelled simultaneously so that their independent associations with food and nutrient intakes could be accounted for, then it might be shown that the overall impact of SEP was larger than that previously estimated owing to the cumulative or additive effects of the different socio-economic measures. Indeed, a number of studies provide direct support for this ${ }^{4,26,27}$.

In this paper, the nature and extent of association between education, occupation, household income and food purchasing behaviour are explored, using a single and then a multiple indicator approach. The analyses demonstrate the importance of conceptualising each measure as making a separate and unique contribution to diet. In addition, we highlight the analytical and interpretation problems that result from examining the relationship between SEP and diet using a single indicator and/or failing to take account of the variance shared by different indicators.

\section{Methods}

The data come from the Brisbane Food Study (BFS), which collected area- and individual-level information to examine the relative contributions of environmental and individual factors to socio-economic variability in food purchasing behaviour. Details of the scope and coverage of the BFS, and its research design, sampling and data collection methods, have been reported in more detail elsewhere $^{28}$.

\section{Sample design}

The BFS used a stratified two-stage cluster sample, comprising 1003 households from 50 small areas, and achieved a $66.4 \%$ response rate.

\section{Data collection}

Data were collected by home-based face-to-face interviews conducted with the person in the household who was most responsible for food shopping. Interviews lasted approximately 1 hour and a small gratuity (AUS\$10) was offered to offset any inconvenience associated with participation in the study. Given that females are typically responsible for a household's food shopping ${ }^{29,30}$, they represented $78 \%$ ( $n=786$ ) of the final sample.

\section{Measures of socio-economic position}

The education measure pertains to the highest qualification completed since leaving school, and comprises four categories: bachelor degree or higher (bachelor degree, postgraduate diploma, masters, doctorate); diploma (associate, undergraduate); vocational (trade or business 
certificate, apprenticeship); and no post-school qualifications.

Occupation information was obtained by asking respondents their employment status at the time of the survey, and, if employed, they were asked their job title and to describe the main tasks and duties performed. This information was coded in accordance with the Australian Standard Classification of Occupations (ASCO) ${ }^{31}$. The ASCO is a skill-based measure that groups occupations according to levels of knowledge required, tools and equipment used, materials worked on, and goods and services produced. The occupational groupings are hierarchically ordered based on the relative skill levels across these different dimensions, with those occupations having the most extensive skill requirements located at the top of the hierarchy. For the purposes of this study, the original nine-level ASCO was re-coded into three categories: managers and professionals (managers and administrators, professionals and associate professionals); white-collar employees (clerical, sales and service); and blue-collar workers (trades, production workers, labourers). In other studies, this three-level indicator has been shown clearly to discriminate between occupation groups in terms of a range of health and social outcomes $^{32,33}$. An additional category, 'not in the labour force', was also created and included the retired, persons doing home duties on a full-time basis, the unemployed, those unable to work and students.

Household income information was obtained by asking respondents to estimate their household's total annual income (including wages, pensions, allowances and gratuities), and to report this using a single measure comprising 14 income categories. The original measure was collapsed into four income groups: AUS\$52000 or more; AUS\$36400 to 51999; AUS\$20 800 to 36399; and less than AUS\$20799. Households in the bottom two categories received incomes at or below the Australian average in 2000 and those in the top two, above the average $^{34}$. Table 1 presents the socio-economic characteristics of the BFS sample.

\section{Food purchasing measures}

Food purchasing behaviour was operationalised using three indices that measured the quality of people's grocery food choices (in terms of fat, fibre, salt and sugar contents), and the frequency and variety of fruit and of vegetable purchases. Grocery food purchasing was examined on the basis of 16 different food types, combined into an index; a detailed description of this measure has been provided in a number of other published studies ${ }^{35,36}$. Briefly, respondents' food purchasing choices were classified into 'recommended' and 'regular' categories (Table 2). The food items in the recommended category are those that health and nutrition authorities suggest are preferable choices to minimise risk for the onset of diet-related disease.
Table 1 Socio-economic characteristics of the Brisbane Food Study sample $(n=1003)$

\begin{tabular}{lrr}
\hline & $n$ & $\%$ \\
\hline Education & & \\
$\quad$ Bachelor degree or higher & 269 & 26.8 \\
Diploma & 105 & 10.5 \\
Vocational & 189 & 18.8 \\
$\quad$ No post-school qualifications & 415 & 41.4 \\
$\quad$ Missing & 25 & 2.5 \\
Occupation & & \\
$\quad$ Managers and professionals & 237 & 23.6 \\
White collar & 226 & 22.5 \\
Blue collar & 77 & 7.7 \\
Not in labour force† & 445 & 44.4 \\
Missingf & 18 & 1.8 \\
Household income (AUS\$) & & \\
52 000 or more & 410 & 40.9 \\
36 400 to 51 999 & 173 & 17.3 \\
20 800 to 36 399 & 207 & 20.6 \\
20799 or less & 185 & 18.4 \\
Missing§ & 28 & 2.8 \\
\hline
\end{tabular}

*Includes three respondents who declined to answer the question, and 22 respondents whose post-school qualifications could not be reliably classified.

† Includes the retired, unemployed, students and those engaged in home duties on a full-time basis.

$\ddagger$ Includes five respondents who declined to answer the question, and 13 whose occupation could not be reliably classified.

$\S$ Includes 24 respondents who declined to answer the income question, and four who did not know the income of other people in their household.

Purchasing patterns for each food type were then scored as follows: respondents never purchased the food (scored 0 ), they purchased the regular option exclusively (scored 1), they purchased a variety of food that included both the recommended and regular options (scored 2) or they purchased the recommended option exclusively (scored 3). The food types were then summed to form a food purchasing index and, using an approach described elsewhere ${ }^{35,36}$, each respondent's index score was standardised on the basis of the number of food types that they usually purchased. The index was subsequently re-scored to range from 0 to 100 (mean 51.2, standard deviation (SD) 17.6, skewness -0.086), with high scores being indicative of greater compliance with dietary guideline recommendations.

Fruit purchasing information was elicited using a question that asked 'When shopping for fresh fruit, how often do you buy these types?' The respondent was instructed to include seasonal fruits, but exclude fruit juice, tinned fruit and dried fruit. The question item set consisted of 19 fruits selected from the food-frequency questionnaire used in the 1995 Australian National Nutrition Survey $^{38}$. Respondents were asked to indicate their usual fruit purchasing pattern on the basis of five-point scales that ranged from never buy (scored 0) to always buy (scored 4). A fruit purchasing index was created by summing the items and scoring the measure to range from 0 to 100 (mean 50.7, SD 18.0, skewness - 0.029), with higher scores indicating a wider variety and greater regularity of fruit purchase. 
Table 2 Classification of 16 food types into 'recommended' and 'regular' categories*

\begin{tabular}{|c|c|c|}
\hline Food type & Recommended $\dagger$ & Regular \\
\hline Bread & $\begin{array}{l}\text { Wholemeal, multigrain, white high in fibre, } \\
\text { rye, soy and linseed }\end{array}$ & White \\
\hline Rice & Wholemeal or brown & White \\
\hline Pasta & Wholemeal or brown & White \\
\hline Baked beans & Salt-reduced or unsalted & Regular salt \\
\hline Fruit juice & No added sugar (unsweetened) & Added sugar, fruit drink (5-35\% fruit juice) \\
\hline Tinned fruit & In natural juice & In syrup \\
\hline Milk & $\begin{array}{l}\text { Reduced-fat (Trim), low-fat (Skim), high-calcium (Physical, } \\
\text { Shape), high-calcium skimmed (Physical), high-iron (Life), } \\
\text { high-protein (Lite White), reduced-lactose (Lactaid), no } \\
\text { cholesterol (Dairy Wise), soy or soy \& linseed (skimmed) }\end{array}$ & $\begin{array}{l}\text { Extra creamy, full cream, soy or } \\
\text { soy \& linseed (full cream) }\end{array}$ \\
\hline Cheese & Reduced-fat ( $25 \%$ less fat), low-fat $(<10 \%$ fat $)$ & Regular fat \\
\hline Yoghurt & Low-fat (plain and fruit) & Regular fat (plain and fruit) \\
\hline Beef mince & Lean (Trim/Premium) & Regular (Choice/Fine Grade) \\
\hline Chicken & $\begin{array}{l}\text { Breast fillet without skin, thigh fillet without skin, } \\
\text { drumstick without skin }\end{array}$ & $\begin{array}{l}\text { Breast fillet with skin, thigh fillet } \\
\text { with skin, drumstick with skin, wings, } \\
\text { whole chicken with skin }\end{array}$ \\
\hline Tinned fish & In spring water & In oil, in brine \\
\hline Vegetable oil & $\begin{array}{l}\text { Canola, sunflower, safflower, olive, corn, soy, } \\
\text { sesame }\end{array}$ & Peanut, sesame, blended edible, macadamia \\
\hline Margarine & Salt-reduced, fat-reduced & Regular salt, regular fat \\
\hline Butter & Salt-reduced, unsalted & Regular salt \\
\hline Solid cooking fat & Margarine, solidified oil & $\begin{array}{l}\text { Solid animal fat (lard, beef dripping), } \\
\text { vegetable shortening }\end{array}$ \\
\hline
\end{tabular}

* Food types were selected on the basis of those included in the five core food groups of the Australian Guide to Healthy Eating ${ }^{37}$ and findings from the 1995 National Nutrition Survey ${ }^{38}$, which indicated that the foods were readily available and consumed by a large proportion of the population.

†Food options endorsed in dietary guideline publications and considered consistent with minimal risk for the development of diet-related diseases.

Vegetable purchasing data were obtained using an identical format and method to that used for fruit. Respondents were asked to indicate how often they purchased 21 vegetables (including fresh and frozen, but excluding tinned or dried) using five-point scales. These were subsequently summed to form an index which was re-scored to range from 0 to 100 (mean 61.8, SD 15.2, skewness - 0.461), with higher scores indicating a wider variety and greater regularity of vegetable purchase.

\section{Analysis}

All analyses exclude respondents with missing values for education, occupation or household income $(n=63)$, and those who reportedly did not purchase fruit $(n=4)$ or vegetables $(n=2)$. The final dataset, therefore, comprised persons who provided complete information on all three socio-economic indicators and food purchasing measures: grocery index $(n=940)$, fruit index $(n=936)$ and vegetable index $(n=938)$.

Data analysis was undertaken in two stages. First, the extent of association among education, occupation and household income was examined using age- and sexadjusted partial product moment correlation coefficients (Pearson's $r$ ). Although each of the socio-economic indicators is measured at the ordinal level, when computing partial measures of ordinal association it is appropriate to utilise the formula for Pearson's correlation $^{39}$. The SAS statistical package was used for these analyses ${ }^{40}$. Second, each of the socio-economic indicators was likely to share variation; thus a relationship between education and food purchasing, for example, was likely to be only partially capturing the direct impact of education per se. The relationship was also likely to be tapping the unmeasured effects of occupation and income. We estimated the magnitude of this likely confounding (and resultant spuriousness) using multiple linear regression. Thus, in the following tables, Model 1 represents the unadjusted effects of education, occupation and income on food choice. We then examined the relationship between SEP and food purchasing using a model that simultaneously adjusted for education and occupation (Model 2), and then for all three socio-economic indicators simultaneously (Model 3). The results of the regression analysis are presented as follows. For each socio-economic indicator, the 'high' group (i.e. bachelor degree or higher, managers and professionals, AUS\$52000 or more) are designated the reference group, and for these we report the age- and sex-adjusted mean food purchasing score. Values for the other socio-economic categories are unstandardised regression coefficients, which represent deviations (plus or minus) in food purchasing score relative to the reference group. The coefficients are presented with their 95\% confidence intervals, and these represent the range of values that includes the 'true' difference in purchasing score between the reference group and the other categories of the socio-economic indicator. Regression coefficients with confidence intervals that are not inclusive of zero are significantly different from the reference group at the 0.05 level. For each regression model, goodness-of-fit is indicated using 
adjusted $R^{2}$ values. Tests for linear trend in food purchasing score across the categories of education and household income were also performed, and the $P$-values associated with these tests are presented with the regression results. $P$-values for tests of trend are not reported for the occupation measure, as 'not in the labour force' represented a non-ordered category for this variable.

Importantly, the two-stage cluster design of the BFS involved sampling small geographic areas that were relatively homogenous in terms of their socio-economic characteristics, and then selecting at random individuals from within each area. As a result, the food purchasing data obtained from those living in the same area was unlikely to be independent. If these data were treated as a simple random sample, and the clustering and associated data dependence ignored, then the standard errors for each socio-economic group would probably be underestimated, and the probability of incurring a type 1 error increased $^{41,42}$. When undertaking the multiple regression, therefore, we accounted for within-area clustering using a generalised estimating equations (GEE) analysis with independent working correlations, that produced food purchasing estimates for each socio-economic group, adjusted for age and sex. The SUDAAN statistical package was used for these analyses ${ }^{43}$.
As part of our analyses, we considered the possibility that the association between SEP and food purchasing behaviour would show a different patterning by gender. This, however, proved to be somewhat the exception rather than the rule. Overall, the socio-economic patterning was similar for males and females, although the results suggested that occupation was a better dietary discriminator for men (an issue returned to in the Discussion). Given this, and to economise on space, we present the results of a combined analysis.

\section{Results}

The age- and sex-adjusted correlations between education and occupation $(r=0.35)$, education and income $(r=$ $0.29)$ and occupation and income $(r=0.46)$ were small to moderate in magnitude. Whilst this provides clear evidence of some shared association, it more importantly suggests that each indicator is likely to make a unique contribution to food purchasing behaviour.

Model 1 in Tables 3-5 shows the unadjusted effects of each socio-economic indicator on the purchase of grocery foods, fruit and vegetables, respectively. Education and household income were significantly associated with all indexes. As the $P$-values for test of trend indicate, these

Table 3 Socio-economic position and grocery purchasing: effects of education, occupation and household income unadjusted for each other (Model 1), simultaneous adjustment for education and occupation (Model 2) and simultaneous adjustment for all three indicators (Model 3) $(n=940)^{\star} \dagger$

\begin{tabular}{|c|c|c|c|c|c|c|}
\hline & \multicolumn{2}{|c|}{ Model 1} & \multicolumn{2}{|c|}{ Model 2} & \multicolumn{2}{|c|}{ Model 3} \\
\hline & $\beta \ddagger$ & $95 \% \mathrm{Cl}$ & $\beta$ & $95 \% \mathrm{Cl}$ & $\beta$ & $95 \% \mathrm{Cl}$ \\
\hline \multicolumn{7}{|l|}{ Education } \\
\hline Bachelor degree or higher & 54.8 & & 54.3 & & 53.3 & \\
\hline Diploma & -4.6 & $-7.7,-1.4$ & -4.6 & $-7.6,-1.7$ & -3.5 & $-6.5,-0.5$ \\
\hline Vocational & -3.4 & $-6.6,-0.1$ & -2.7 & $-5.9,0.6$ & -1.3 & $-4.6,2.0$ \\
\hline No post-school qualifications & -5.2 & $-8.2,-2.3$ & -4.3 & $-6.9,-1.8$ & -3.1 & $-5.5,-0.6$ \\
\hline $\begin{array}{l}P \text {-value for test of trend } \\
R^{2}\end{array}$ & $\begin{array}{l}0.0026 \\
0.05\end{array}$ & & 0.0468 & & 0.1578 & \\
\hline \multicolumn{7}{|l|}{ Occupationף } \\
\hline Managers and professionals & 54.7 & & 53.3 & & 52.0 & \\
\hline White collar & -0.6 & $-4.2,2.9$ & 1.4 & $-2.1,4.9$ & 1.8 & $-1.7,5.3$ \\
\hline Blue collar & -5.4 & $-10.4,-0.4$ & -3.0 & $-8.0,2.1$ & -2.1 & $-7.2,2.9$ \\
\hline Not in labour force & -6.1 & $-9.4,-2.8$ & -4.4 & $-7.5,-1.4$ & -2.0 & $-5.1,1.1$ \\
\hline$R^{2}$ & 0.05 & & 0.06 & & & \\
\hline \multicolumn{7}{|l|}{ Household income (AUS\$) } \\
\hline 52000 or more & 55.5 & & & & 54.6 & \\
\hline 36400 to 51999 & -4.9 & $-8.0,-1.7$ & & & -3.9 & $-6.9,-0.9$ \\
\hline 20800 to 36399 & -6.9 & $-10.6,-3.2$ & & & -5.7 & $-9.2,-2.1$ \\
\hline 20799 or less & -9.3 & $-13.2,-5.4$ & & & -6.8 & $-11.2,-2.4$ \\
\hline$P$-value for test of trend & 0.0001 & & & & 0.0003 & \\
\hline$R^{2}$ & 0.07 & & & & 0.08 & \\
\hline
\end{tabular}

${ }^{*}$ All analyses also adjusted for age and sex.

† Grocery purchasing index ranged from 0 to 100 (mean 51.2, standard deviation 17.6), with high scores indicating greater compliance with dietary guideline recommendations.

‡The figures for each reference group (i.e. bachelor degree or higher, managers and professionals, AUS $\$ 52000$ or more) represent age- and sex-adjusted mean grocery purchasing scores. Values for the other socio-economic categories are unstandardised regression coefficients, which represent average deviations (plus or minus) in food purchasing score relative to the reference group.

$\$ 95 \%$ confidence interval. Regression coefficients with confidence intervals that are not inclusive of zero are significantly different from the reference group at the 0.05 level. Example: in Model 1, for those with no post-school qualifications, we can be $95 \%$ confident that the interval $-8.2,-2.3$ includes the 'true' difference in grocery purchasing score for this group relative to the reference group. In other words, the score for the least educated lies somewhere in the range 46.6-52.5.

I $P$-values for test of trend were not reported for the occupation measure, as 'not in the labour force' represented a non-ordered category for this variable. 
Table 4 Socio-economic position and fruit purchasing: effects of education, occupation and household income unadjusted for each other (Model 1), simultaneous adjustment for education and occupation (Model 2) and simultaneous adjustment for all three indicators (Model 3) $(n=936)^{*} \dagger$

\begin{tabular}{|c|c|c|c|c|c|c|}
\hline & \multicolumn{2}{|c|}{ Model 1} & \multicolumn{2}{|c|}{ Model 2} & \multicolumn{2}{|c|}{ Model 3} \\
\hline & $\beta \ddagger$ & $95 \% \mathrm{Cl} \S$ & $\beta$ & $95 \% \mathrm{Cl}$ & $\beta$ & $95 \% \mathrm{Cl}$ \\
\hline \multicolumn{7}{|l|}{ Education } \\
\hline Bachelor degree or higher & 52.7 & & 52.8 & & 51.7 & \\
\hline Diploma & -1.1 & $-4.8,2.5$ & -1.4 & $-5.0,2.1$ & -0.2 & $-3.8,3.5$ \\
\hline Vocational & -1.1 & $-4.6,2.2$ & -1.6 & $-5.1,2.0$ & 0.0 & $-3.6,3.7$ \\
\hline No post-school qualifications & -4.0 & $-6.5,-1.6$ & -4.3 & $-6.9,-1.6$ & -2.6 & $-5.2,0.1$ \\
\hline $\begin{array}{l}P \text {-value for test of trend } \\
R^{2}\end{array}$ & $\begin{array}{l}0.0036 \\
0.12\end{array}$ & & 0.0085 & & 0.0675 & \\
\hline \multicolumn{7}{|l|}{ Occupation } \\
\hline Managers and professionals & 51.5 & & 50.1 & & 48.7 & \\
\hline White collar & -0.1 & $-3.2,3.0$ & 1.7 & $-1.4,4.9$ & 1.9 & $-1.2,5.1$ \\
\hline Blue collar & -3.8 & $-8.0,0.5$ & -1.4 & $-5.7,2.8$ & -1.0 & $-5.3,3.4$ \\
\hline Not in labour force & -1.3 & $-3.8,1.2$ & 0.4 & $-2.3,3.1$ & 3.5 & $0.6,6.3$ \\
\hline$R^{2}$ & 0.12 & & 0.13 & & & \\
\hline \multicolumn{7}{|l|}{ Household income (AUS\$) } \\
\hline 52000 or more & 53.4 & & & & 53.9 & \\
\hline 36400 to 51999 & -0.4 & $-3.0,2.2$ & & & -0.7 & $-3.6,2.1$ \\
\hline 20800 to 36399 & -5.8 & $-9.0,-2.5$ & & & -6.4 & $-9.8,-3.1$ \\
\hline 20799 or less & -8.8 & $-11.7,-5.8$ & & & -9.7 & $-13.2,-6.2$ \\
\hline$P$-value for test of trend & 0.0001 & & & & 0.0001 & \\
\hline$R^{2}$ & 0.15 & & & & 0.16 & \\
\hline
\end{tabular}

${ }^{\star}$ All analyses also adjusted for age and sex.

†Fruit purchasing index ranged from 0 to 100 (mean 50.7, standard deviation 18.0), with high scores indicating a wider variety and greater regularity of fruit purchase.

¥The figures for each reference group (i.e. bachelor degree or higher, managers and professionals, AUS $\$ 52,000$ or more) represent age- and sex-adjusted mean fruit purchasing score. Values for the other socio-economic categories are unstandardised regression coefficients, which represent average deviations (plus or minus) in fruit purchasing score relative to the reference group.

$\$ 95 \%$ confidence interval. Regression coefficients with confidence intervals that are not inclusive of zero are significantly different from the reference group at the 0.05 level. Example: in Model 1, for those with no post-school qualifications, we can be $95 \%$ confident that the interval $-6.5,-1.6$ includes the 'true' difference in fruit purchasing score for this group relative to the reference group. In other words, the score for the least educated lies somewhere in the range 46.2-51.1.

I $P$-values for test of trend were not reported for the occupation measure, as 'not in the labour force' represented a non-ordered category for this variable.

relationships often showed a graded pattern across the levels of each socio-economic group, with the least educated and residents of low-income households being less likely to have a purchasing profile consistent with healthy food purchasing messages. Occupation was significantly related with the grocery index, and nonsignificantly associated with fruit and vegetable purchasing. The magnitude of difference in index score across the levels of each socio-economic indicator suggests that household income was the strongest unadjusted predictor of food choice.

The results for Model 2, which represents food purchasing scores simultaneously adjusted for education and occupation, show a reduction in the magnitude of effects of these socio-economic indicators on food choice when compared with those found prior to adjustment (Model 1), although the overall patterning of results remained the same. Education influenced purchasing behaviour independent of occupation for all three food indexes, whereas occupation was independently associated only with grocery purchasing. Simultaneous adjustment for all three socio-economic indicators further reduced the impact of education and occupation on food purchasing behaviour (Model 3): as indicated by the 95\% confidence intervals, independent effects were now found only between education and grocery purchasing (Table 3) and occupation and fruit purchasing (Table 4). No significant (independent) effects were observed between education, occupation and vegetable purchasing after simultaneous adjustment for each socio-economic indicator (Table 5, Model 3). Household income, however, remained robust in its relationship with food purchasing after adjustments for education and occupation. Independent graded associations were observed between household income and the purchase of grocery foods and fruit and vegetables, with those in low-income households being least likely to exhibit a purchasing pattern consistent with nutrition messages. The attenuation of household income's relationship with grocery purchasing for Model 3 (Table 3) suggests that, prior to adjustment, this socioeconomic indicator was also encapsulating the unmeasured effects of education and occupation on choice of this food type. Conversely, the strengthened association between income and fruit purchasing after adjustments for education and occupation (Table 4, Model 3) points to the likely suppressor effect of these socio-economic indicators in terms of obfuscating the underlying links between income level and fruit choice. 
Table 5 Socio-economic position and vegetable purchasing: effects of education, occupation and household income unadjusted for each other (Model 1), simultaneous adjustment for education and occupation (Model 2) and simultaneous adjustment for all three indicators (Model 3$)(n=938)^{*} \dagger$

\begin{tabular}{|c|c|c|c|c|c|c|}
\hline & \multicolumn{2}{|c|}{ Model 1} & \multicolumn{2}{|c|}{ Model 2} & \multicolumn{2}{|c|}{ Model 3} \\
\hline & $\beta \neq$ & $95 \% \mathrm{CI}$ & $\beta$ & $95 \% \mathrm{Cl}$ & $\beta$ & $95 \% \mathrm{Cl}$ \\
\hline \multicolumn{7}{|l|}{ Education } \\
\hline Bachelor degree or higher & 62.9 & & 62.9 & & 62.2 & \\
\hline Diploma & 1.3 & $-2.0,4.7$ & 1.2 & $-2.1,4.4$ & 1.8 & $-1.4,5.0$ \\
\hline Vocational & 0.4 & $-2.2,3.0$ & 0.5 & $-2.4,3.3$ & 1.2 & $-1.6,4.1$ \\
\hline No post-school qualifications & -3.2 & $-5.3,-1.1$ & -3.0 & $-5.4,-0.7$ & -2.1 & $-4.4,0.3$ \\
\hline$P$-value for test of trend & 0.0044 & & 0.0177 & & 0.0611 & \\
\hline$R^{2}$ & 0.08 & & & & & \\
\hline \multicolumn{7}{|l|}{ Occupationף } \\
\hline Managers and professionals & 62.8 & & 62.0 & & 61.3 & \\
\hline White collar & 0.6 & $-2.0,3.1$ & 1.5 & $-1.2,4.2$ & 1.4 & $-1.3,4.0$ \\
\hline Blue collar & -4.2 & $-8.7,0.3$ & -2.7 & $-7.4,2.0$ & -2.6 & $-7.2,2.0$ \\
\hline Not in labour force & -1.8 & $-3.9,0.4$ & -0.7 & $-3.0,1.6$ & 1.0 & $-1.3,3.2$ \\
\hline$R^{2}$ & 0.08 & & 0.09 & & & \\
\hline \multicolumn{7}{|l|}{ Household income (AUS\$) } \\
\hline 52000 or more & 63.4 & & & & 63.4 & \\
\hline 36400 to 51999 & 0.0 & $-2.5,2.6$ & & & 0.1 & $-2.5,2.7$ \\
\hline 20,800 to 36399 & -1.6 & $-4.3,1.1$ & & & -1.8 & $-4.5,0.9$ \\
\hline 20799 or less & -6.6 & $-9.6,-3.6$ & & & -6.4 & $-9.5,-3.3$ \\
\hline$P$-value for test of trend & 0.0003 & & & & 0.0013 & \\
\hline$R^{2}$ & 0.09 & & & & 0.10 & \\
\hline
\end{tabular}

${ }^{*}$ All analyses also adjusted for age and sex.

† Vegetable purchasing index ranged from 0 to 100 (mean 61.8, standard deviation 15.2), with high scores indicating a wider variety and greater regularity of vegetable purchase.

¥The figures for each reference group (i.e. bachelor degree or higher, managers and professionals, AUS $\$ 52000$ or more) represent ageand sex-adjusted mean vegetable purchasing scores. Values for the other socio-economic categories are unstandardised regression coefficients, which represent average deviations (plus or minus) in vegetable purchasing score relative to the reference group.

$\$ 95 \%$ confidence interval. Regression coefficients with confidence intervals that are not inclusive of zero are significantly different from the reference group at the 0.05 level. Example: in Model 1, for those with no post-school qualifications, we can be $95 \%$ confident that the interval $-5.3,-1.1$ includes the 'true' difference in vegetable purchasing score for this group relative to the reference group. In other words, the score for the least educated lies somewhere in the range 57.6-61.8.

I $P$-values for test of trend were not reported for the occupation measure, as 'not in the labour force' represented a non-ordered category for this variable.

\section{Discussion}

Our review of the diet-related literature showed that few researchers provide an explicit rationale or justification for their choice of socio-economic indicator. Moreover, many researchers seemingly make the unstated assumption that each indicator is tapping a similar underlying construct (i.e. they are surrogates) and can hence be used interchangeably. This is reflected in studies that investigate the relationship between SEP and diet on the basis of a single indicator even when other indicators are reported by the authors as being available ${ }^{44,45}$. The interchangeability assumption is also evident in studies that employ more than one measure of SEP, but use each separately, and therefore fail to take account of the covariance that exists between different measures ${ }^{21-24,45,46}$. As outlined in the introduction, these common practices in the treatment of SEP are likely to produce biased estimates for individual indicators, and hence misstate the overall degree of dietary differences between socio-economic groups ${ }^{47}$.

The findings of this present study challenge some of these current practices and assumptions about the conceptualisation and use of SEP in dietary research, and, therefore, suggest ways of minimising the types of bias discussed earlier. As part of our analyses, we explored the hypothesis that education, occupation and household income each uniquely contributes to food purchasing behaviour, thus providing indirect support for the notion that each reflects a different underlying process. A correlation analysis found that the three socio-economic indicators were weakly to moderately related, which, while suggesting some shared association with purchasing behaviour, more importantly highlighted the likely substantial separate contribution of each indicator to food choice.

The second stage of this study's analysis used linear regression to examine the independent contribution of each socio-economic indicator to purchasing behaviour. The findings for Model 1, which pertained to the effects of education, occupation and household income unadjusted for each other, showed that each indicator was significantly related to one or more of the food indices. This initial analysis, however, took no account of the fact that the three socio-economic indicators were correlated, and hence the regression coefficients were likely to have been biased. This was supported by the findings of Model 2, which simultaneously adjusted for education and occupation, resulting in a substantial attenuation of the regression coefficients for these indicators when compared with those generated for Model 1. Therefore, had 
this study relied solely on the results of Model 1 to assess the relationship between SEP and food purchasing, we would have misstated our claims about the influence of education and occupation on food choice. This in turn would have led to somewhat distorted conclusions, with consequent negative implications for the end-users of the information, such as developers of healthy eating messages.

Previous studies have suggested that education is the most stable indicator of SEP as it captures processes that occur early in life and that tend not to change over time ${ }^{1}$. The relationship between education and diet is presumed to reflect a person's ability (or otherwise) to access and interpret health-related information ${ }^{4}$. Occupation has been used in a number of dietary studies, and, like in this present investigation, it is often reported that respondents in blue-collar (manual) occupations have dietary profiles that are least consistent with recommended practices ${ }^{7,25-27,45,46,48}$. Occupation is believed to influence dietary behaviour partly via workplace cultures and social networks ${ }^{4}$. However, the use of occupation in dietary research is beset with a number of problems $^{1-3}$, two of which may have contributed to the mixed findings for occupation reported in this study. Firstly, our decision to interview the person in each household who was primarily responsible for food purchasing resulted in a final sample that was $78 \%$ female. Traditionally, occupation-based measures have been developed and operationalised using employed males ${ }^{1,3}$. However, in light of evidence showing that these occupation measures produce less consistent results for women $^{27}$, their appropriateness for use with employed females is being questioned ${ }^{1,3}$. Secondly, occupation measures cannot be reliably used for social groups outside the paid workforce, such as the unemployed, full-time homemakers, the retired, students and those in informal sectors of the economy ${ }^{1}$. In this present study, $44.4 \%$ of the sample were classified as 'not in the labour force' (partly reflecting the large proportion of females), and given the heterogeneity of this group it may have attenuated the occupation effect, and certainly presented problems with interpretation.

The regression analysis showed household income to be the strongest and most robust independent predictor of food purchasing behaviour, which is not too surprising given the now well established links between economic and material resources, food availability and dietary quality $^{15,16,49}$. By contrast, the effects of education and occupation on food purchasing were substantially attenuated (to non-significance or marginal significance) after adjustments were made for household income. A number of factors might have contributed to this, including extraneous confounding and misclassification bias. The continued strength of association between income and food purchasing after adjustment for education and occupation might also be due to income and purchasing being measured at the same level (i.e. household). The specificity of this relationship, therefore, was greater and more direct than between education, occupation and purchasing, which were measured at different levels (i.e. individual and household). Associations between education, occupation and purchasing presumably reflect each respondent's own (individual) contribution to food choice for the household, whereas household income was possibly capturing the combined contextual effects of numerous individuals, as well as many other within-household processes, and thus showed a stronger relationship with purchasing.

The main substantive finding of this study was that people from socio-economically disadvantaged backgrounds were less likely to buy grocery foods that were high in fibre and low in fat, salt and sugar. In addition, the least educated, those employed in blue-collar jobs and residents of low-income households purchased fewer types of fresh fruit and vegetables, and less regularly, than their counterparts from more advantaged backgrounds. A number of factors probably account for these socioeconomic differences in diet. Health promotion efforts aimed at encouraging the adoption of a healthy diet may have been more successful with socio-economically advantaged groups. This interpretation is consistent with conclusions reached by researchers examining the relationship between SEP and other health-related behaviours and outcomes ${ }^{50,51}$. Our results also possibly reflect the greater structural, material and economic difficulties faced by disadvantaged groups when procuring food. Low-income groups, for example, have been shown disproportionately to live in areas where there are fewer large supermarkets ${ }^{52}$. As a consequence, these groups are more reliant on smaller shops, which typically stock a limited range of foods, their food prices are often higher than in large supermarkets, and fresh food is often of a lesser quality ${ }^{17,53}$. Disadvantaged groups may also experience greater difficulties obtaining access to large (and distant) shopping facilities because they lack private transport, or live in areas where public transport is inadequate or non-existent ${ }^{15,29}$. Furthermore, foods that are recommended in dietary guideline health promotion messages might be too expensive for economically disadvantaged groups ${ }^{16,17}$.

It is also important to note that the socio-economic differences reported in this paper were based on a response rate of $66.4 \%$. We know from previous research into survey participation that population-based samples typically under-represent the most socio-economically disadvantaged and over-represent the advantaged ${ }^{54}$. Thus the socio-economic differences in food purchasing choice presented here, while significant, are likely to be an underestimate of the 'true' magnitude of socio-economic differences in food choice in the Brisbane population.

In summary, the findings of this study suggest that education, occupation and household income are distinct 
socio-economic constructs, with different conceptual underpinnings, that reflect influences operating at different levels; for these reasons, the measures are not conceptually interchangeable. Researchers should therefore, when possible, use a number of socio-economic indicators as part of their analyses, as each tells us something different about how SEP influences diet. In addition, where appropriate, or when sample sizes permit, measures of SEP should be modelled in a way that enables their independent contribution to dietary behaviour to be estimated accurately. Our understanding of the relationship between SEP and diet is likely to be improved as a result.

\section{Acknowledgements}

Funding for this research was provided by a National Health and Medical Research Council Project Grant (No. 101217) and support from the Victorian Health Promotion Foundation (VicHealth). Dr Turrell is a Senior Research Fellow supported by a National Health and Medical Research Council/National Heart Foundation Career Development Award (CR 01B 0502).

\section{References}

1 Berkman LF, Macintyre S. The measurement of social class in health studies: old measures and new formulations. IARC Scientific Publications 1997; 138: 51-64.

2 Liberatos P, Link BG, Kelsey JL. The measurement of social class in epidemiology. Epidemiol. Rev. 1988; 10: 87-121.

3 Krieger N, Williams DR, Moss NE. Measuring social class in US public health research: concepts, methodologies and guidelines. Annu. Rev. Public Health 1997; 18: 341-78.

4 Galobardes B, Morabia A, Bernstein M. Diet and socioeconomic position: does the use of different indicators matter? Int. J. Epidemiol. 2001; 30: 334-40.

5 Milligan RA, Burke V, Beilin LJ, Dunbar DL, Spencer MJ Balde E. Influence of gender and socioeconomic status on dietary patterns and nutrient intakes in 18 year old Australians. Aust. NZ J. Public Health 1998; 25: 389-95.

6 Bergstrom E, Hernell O, Persson L. Cardiovascular risk indicators in girls from families of low socioeconomic status. Acta Paediatr. 1996; 85: 1083-90.

7 Billson H, Pryer JA, Nichols R. Variation in fruit and vegetable consumption among adults in Britain: an analysis from the Dietary and Nutritional Survey of British Adults. Eur. J. Clin. Nutr. 1999; 53: 946-52.

8 De Irala-Estevez J, Groth M, Johansson L, Oltersdorf U, Prattala R, Martinez-Gonzalez MA. A systematic review of socioeconomic differences in food habits in Europe: consumption of fruit and vegetables. Eur. J. Clin. Nutr 2000; 54: 706-14.

9 Rankin JW, Winett RA, Anderson ES, Bickley PG, Moore JF, Leahy $\mathrm{M}$, et al. Food purchase patterns at the supermarket and their relationship to family characteristics. J. Nutr. Educ. 1998; 30: 81-8.

10 Turrell G. Socioeconomic differences in food preference and their influence on healthy food purchasing choices. J. Hum Nutr. Diet. 1998; 11: 135-49.

11 Turrell G, Western JS, Najman JM. The measurement of social class in health research: problems and prospects. In: Waddell C, Petersen AR, eds. Just Health: Inequality in Illness, Care and Prevention. Melbourne: Churchill Livingstone, 1994; 87-103.

12 Lynch J, Kaplan G. Socioeconomic position. In: Berkman LF, Kawachi I, eds. Social Epidemiology. New York: Oxford University Press, 2000; 13-35.

13 Macario E, Emmons KM, Sorensen G, Hunt MK, Rudd RE. Factors influencing nutrition education for patients with low literacy skills. J. Am. Diet. Assoc. 1998; 98: 559-64.

14 Busselman KM, Holcomb CA. Reading skill and comprehension of Dietary Guidelines by WIC participants. J. Am. Diet. Assoc. 1994; 94: 622-5.

15 Robinson N, Caraher M, Lang T. Access to shops: the views of low-income shoppers. Health Educ. J. 2000; 59: 121-36.

16 Barratt $J$. The cost and availability of healthy food choices in southern Derbyshire. J. Hum. Nutr. Diet. 1997; 10: 63-9.

17 Sooman A, Macintyre S, Anderson A. Scotland's health - a more difficult challenge for some? The price and availability of healthy foods in socially contrasting localities in the West of Scotland. Health Bull. 1993; 51: 276-84.

18 Najman JM. The measurement of socioeconomic inequality and social class in Australia: a review of past practices and recent developments. Community Health Stud. 1988; 12: $31-41$.

19 Winkelby MA, Jatulis DE, Frank E, Fortmann SP. Socioeconomic status and health: how education, income and occupation contribute to risk factors for cardiovascular disease. Am. J. Public Health 1992; 82: 816-20.

20 Abramson JH, Gofin R, Habib J, Pridan H, Gofin J. Indicators of social class: a comparative appraisal of measures for use in epidemiological studies. Soc. Sci. Med. 1982; 16: 1739-46.

21 Auld GW, Bruhn CM, McNulty J, Bock MA, Gabel K, Lauritzen G, et al. Reported adoption of dietary fat and fiber recommendations among consumers. J. Am. Diet. Assoc. 2000; 100: $52-8$.

22 Shi L. Sociodemographic characteristics and individual health behaviours. S. Med. J. 1998; 91: 933-41.

23 Dobson A, Porteous J, McElduff P, Alexander H. Whose diet has changed? Aust. NZ J. Public Health 1997; 21: 147-54.

24 Thompson B, Denmark-Wahnefried W, Taylor G, McClelland JW, Stables G, Havas S, et al. Baseline fruit and vegetable intake among adults in seven 5 a day study centers located in diverse geographic areas. J. Am. Diet. Assoc. 1999; 99: $1241-48$.

25 Lindstrom M, Hanson BS, Wirfalt E, Ostergren PO. Socioeconomic differences in the consumption of vegetables, fruit and fruit juices: the influence of psychosocial factors. Eur. J. Public Health 2001; 11: 51-9.

26 Bolton-Smith C, Smith WCS, Woodward M, Tunstall-Pedoe H. Nutrient intakes of different social-class groups: results from the Scottish Heart Health Study (SHHS). Br. J. Nutr. 1991; 65: 321-35.

27 Evans A, Booth H, Cashel K. Sociodemographic determinants of energy, fat and dietary fibre intake in Australian adults. Public Health Nutr. 2000; 3: 67-75.

28 Turrell G, Patterson C, Oldenburg B, Gould T, Roy M-A. The socio-economic patterning of survey participation and nonresponse error in a multilevel study of food purchasing behaviour: area- and individual-level characteristics. Public Health Nutr. 2003; 6: 179-187.

29 Caraher M, Dixon P, Lang T, Car-Hill R. Access to healthy foods: part I. Barriers to accessing healthy foods: differentials by gender, social class, income and mode of transport. Health Educ. J. 1998; 57: 191-201.

30 Turrell G. Determinants of gender differences in dietary behavior. Nutr. Res. 1997; 17: 1105-20.

31 Australian Bureau of Statistics. Australian Standard Classification of Occupations, 2nd ed. Catalogue No. 1220.0 Canberra: Australian Government Publishing Service, 1997. 
32 Turrell G, Battistutta D, McGuffog I. Social determinants of smoking among parents with infants. Aust. NZ J. Public Health 2002; 26: 30-7.

33 Turrell G. Income non-reporting: implications for health inequalities research. J. Epidemiol. Community Health 2000; 54: $166-72$.

34 Australian Bureau of Statistics. Income Distribution 19992000. Catalogue No. 6523.0. Canberra: Australian Government Publishing Service, 2001.

35 Turrell G. Determinants of healthy food choice in a population-based sample. Am. J. Health Behav. 1998; 22: 342-57.

36 Turrell G. Compliance with the Australian dietary guidelines in the early 1990's: have population-based health promotion programs been effective? Nutr. Health 1997; 11: 271-88.

37 Commonwealth Department of Health and Family Services. Australian Guide to Healthy Eating. Canberra: Australian Government Publishing Service, 1998.

38 McLennan W. National Nutrition Survey User's Guide. Canberra: Australian Government Publishing Service, 1998.

39 Blalock HM. Social Statistics. Tokyo: McGraw Hill, 1981; 462.

40 SAS Institute, Inc. SAS/STAT Software: Changes and Enhancements through Release 6.12. Cary, NC: SAS Institute, Inc., 1997.

41 Korn EL, Graubard BI. Analysis of large health surveys: accounting for the sampling design. J. Roy. Statist. Soc. 1995; 158: $263-95$.

42 Carlin JB, Hocking J. Design of cross-sectional surveys using cluster sampling: an overview with Australian case studies. Aust. NZ J. Public Health 1999; 23: 546-51.

43 Research Triangle Institute. SUDAAN User's Manual, Release 8.O. Research Triangle Park, NC: Research Triangle Institute, 2001
44 Shimakawa T, Sorlie P, Carpenter MA, Dennis B, Tell GS, Watson R, et al. Dietary intake patterns and sociodemographic factors in the Atherosclerosis Risk in Communities Study. Prev. Med. 1994; 23: 769-80.

45 Roos E, Lahelma E, Virtanen M, Prattala R, Pietinen P Gender, socioeconomic status and family status as determinants of food behaviour. Soc. Sci. Med. 1998; 46: 1519-29.

46 Smith AM, Baghurst KI. Public health implications of dietary differences between social status and occupational category groups. J. Epidemiol. Community Health 1992; 46: 409-16.

47 Shaw M, Dorling D, Gordon D, Smith GD. The Widening Gap: Health Inequalities and Policy in Britain. Bristol: Policy Press, 1999

48 Tseng M, DeVellis RF. Fundamental dietary patterns and their correlates among US whites. J. Am. Diet. Assoc. 2001; 101: 929-32.

49 Kinsey JD. Food and families' socioeconomic status. J. Nutr. 1994; 124: 1878S-85S.

50 Benzeval M, Judge K, Whitehead M. Tackling Inequalities in Health: An Agenda for Action. London: King's Fund, 1995.

51 Kawachi I, Marmot MG. What can we learn from studies of occupational class and cardiovascular disease? Am. J. Epidemiol. 1998; 148: 160-3.

52 Curtis KA, McClellan S. Falling through the safety net: poverty, food assistance and shopping constraints in an American city. Urban Anthropol. 1995; 24: 93-135.

53 Ellaway A, Macintyre S. Shopping for food in socially contrasting localities. Br. Food J. 2000; 102: 52-9.

54 Turrell G, Najman JM. Collecting food-related data from low socioeconomic groups: how adequate are our current research designs? Aust. J. Public Health 1995; 19: 410-6. 